Antonie van Leeuwenhoek 54: 575 (1988)

(C) Kluwer Academic Publishers, Dordrecht - Printed in the Netherlands

\title{
Erratum
}

Antonie van Leeuwenhoek Vol. 54, No. 2 (1988) pp. 139-148

\section{Comparative use of amino acids by three auxotypes of Neisseria gonorrhoeae}

\author{
L. PILLON, M. CHAN, J. FRANCZYK \& M. GOLDNER \\ Dept. of Microbiology, Universiry of Toronto, Ontario M5S 1A8, Canada
}

On page 141 in Fig. 1a the $1.29 \mathrm{mM} /$ ( $3 \times$ NEDF) points were not included in the graph. Below is given the correct presentation of the Figure.

a

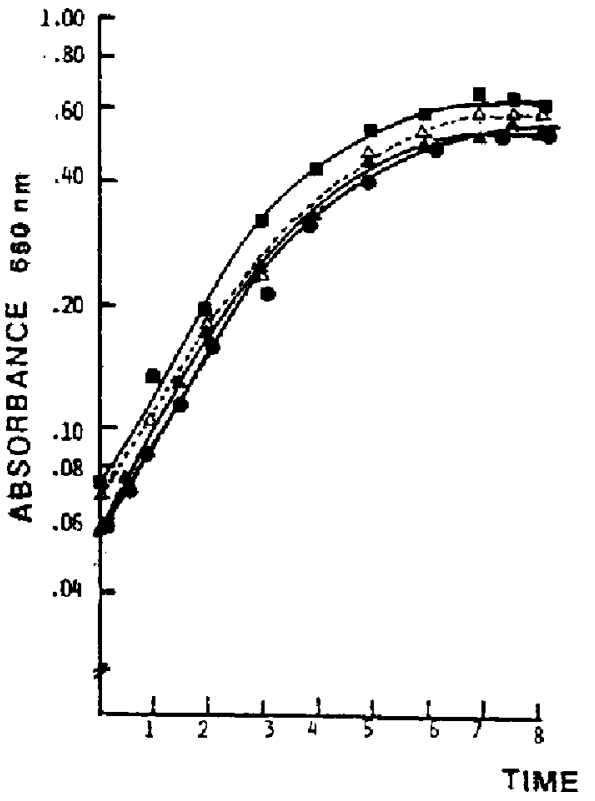

b

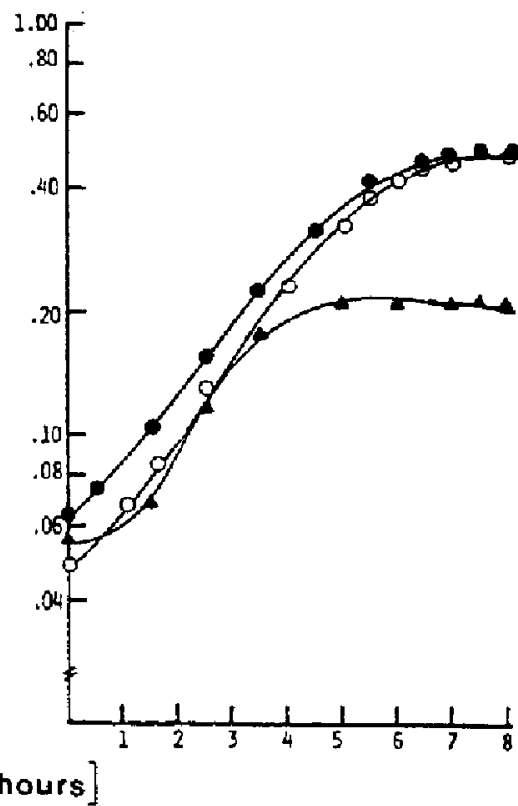

Fig. 1. Representative growth curves for $N$. gonorrhoeae strains in NEDF. (a) The prototype was grown in NEDF having the following proline concentrations: $\square$ proline absent, $\$ 0.43 \mathrm{mM} / \mathrm{l}$ (nomal NEDF proline concentration), $1.29 \mathrm{mM} / 1$ (3× NEDF). Thia- in the different concentrations of proline is represented as such $--\Delta--$. (b) The pro- was grown in different concentrations of proline: $\triangle 0.43 \mathrm{mM} / 1,1.29 \mathrm{mM} / \mathrm{l}(3 \times \mathrm{NEDF}), \mathrm{O} 1.72 \mathrm{mM} / \mathrm{l}(4 \times \mathrm{NEDF})$. 